\section{JURNAL EKONOMI EFEKTIF}

ISSN : $2622-8882$, E-ISSN : 2622-9935

Jurnal Ekonomi Efektif, Vol. 3, No. 3, April 2021

@ Prodi Manajemen Fakultas Ekonomi Universitas

Pamulang

\title{
PENGARUH PELATIHAN TERHADAP KINERJA KARYAWAN PADA PT. ESSAR DHANANJAYA DI CIBITUNG - BEKASI
}

\author{
Muhammad Abdul Rajak \\ Universitas Pamulang, Tangerang Selatan, Banten, Indonesia \\ dosen02396@unpam.ac.id
}

Manuskrip: Mar-2021 Ditinjau: Mar-2021; Diterima: Mar-2021; Online: Apr-2021; Diterbitkan: Apr-2021

\begin{abstract}
ABSTRAK
Penelitian ini bertujuan untuk mengetahui pengaruh pelatihan terhadap kinerja karyawan pada PT. Essar Dhananjaya di Cibitung-Bekasi. Metode yang digunakan adalah explanatory research dengan sampel sebanyak 100 responden. Teknik analisis menggunakan analisis statistik dengan pengujian regresi, korelasi, determinasi dan uji hipotesis. Hasil penelitian ini variabel pelatihan diperoleh nilai rata-rata skor sebesar 3,41 dengan kriteria baik. Variabel kinerja karyawan diperoleh nilai rata-rata skor sebesar 3,84 dengan kriteria baik. Pelatihan berpengaruh positif dan signifikan terhadap kinerja karyawan dengan nilai persamaan regresi $\mathrm{Y}=9,323+0,852 \mathrm{X}$, dan nilai koefisien korelasi 0,777 atau memiliki tingkat hubungan yang kuat dengan nilai determinasi 60,3\%. Uji hipotesis diperoleh signifikansi $0,000<0,05$.
\end{abstract}

Kata Kunci: Pelatihan, Kinerja Karyawan.

\begin{abstract}
This study aims to determine the effect of training on employee performance at PT. Essar Dhananjaya in Cibitung-Bekasi. The method used is explanatory research with a sample of 100 respondents. The analysis technique uses statistical analysis with regression testing, correlation, determination and hypothesis testing. The results of this study the training variable obtained an average score of 3.41 with good criteria. Employee performance variables obtained an average score of 3.84 with good criteria. Training has a positive and significant effect on employee performance with the regression equation $Y=9.323+0.852 X$, and the correlation coefficient value is 0.777 or has a strong level of relationship with a determination value of $60.3 \%$. Hypothesis testing obtained a significance of $0.000<0.05$.
\end{abstract}

Keywords: Training, Employee Performance. 


\section{PENDAHULUAN}

\section{A. Latar Belakang Masalah}

Sumber daya manusia (SDM) merupakan salah satu faktor kunci dalam reformasi ekonomi, yakni bagaimana menciptakan SDM yang berkualitas dan memiliki keterampilan serta berdaya saing tinggi dalam persaingan global yang selama ini kita abaikan. Dalam kaitan tersebut setidaknya kita harus tau kondisi sumber daya manusia sekarang ini dan permasalahan yang dialami Indonesia mengenai SDM-nya. Adapun permasalahan SDM Indonesia adalah sekarang ini adanya ketimpangan antara jumlah kesempatan kerja dan angkatan kerja, tingkat pendidikan angkatan kerja yang ada masih relatif rendah, lesunya dunia usaha akibat krisis ekonomi yang berkepanjangan sampai saat ini mengakibatkan rendahnya kesempatan kerja terutama bagi lulusan perguruan tinggi, lemahnya perguruan tinggi dalam menciptakan SDM yang handal professional dan punya daya saing tinggi, belum adanya kesadaran bagi pemerintah bangsa Indonesia untuk memperbaiki SDM Indonesia, dilihat dari rendahnya alokasi APBN untuk sektor pendidikan tidak lebih dari $12 \%$ pada pemerintahan di era reformasi.

Perusahaan atau organisasi memiliki berbagai macam instrument dalam mencapai tujuannya. Instrument-instrumen tersebut seperti sumber daya manusia, teknologi dan modal. Namun instrumen yang paling penting sebenarnya adalah sumber daya manusia, dimana manusia merupakan faktor penggerak terpenting dari roda organisasi atau perusahaan. Perusahaan sangat membutuhkan sumber daya manusia yang kompeten dan berkualitas, terutama di era globalisasi sekarang ini.

Penggunaan tenaga kerja yang efektif dan terarah merupakan kunci kearah peningkatan kinerja karyawan sehingga dibutuhkan suatu kebijakan perusahaan untuk penggerak karyawan agar mau bekerja lebih produktif sesuai dengan rencana yang telah diterapkan. Jadi sesudah karyawan direkrut, dipilih dan dilantik selanjutnya dikembangkan agar lebih sesuai dengan pekerjaan dan organisasi. Salah satu upaya yang dapat dilakukan perusahaan untuk meningkatkan kualitas karyawan dari perusahaan PT. Essar Dhananjaya adalah dengan melakukan training atau pelatihan dengan materi yang sesuai diharapkan.

Pelatihan dipandang sebagai suatu usaha yang terencana dari perusahaan untuk meningkatkan pengetahuan, keterampilan dan kemampuan karyawan terhadap kinerja karyawan di PT. Essar Dhananjaya. Dengan pelaksanaan pelatihan yang tepat, maka perusahaan diharapkan dapat memperbaiki efektivitas dan kinerja karyawan dalam mencapai hasil-hasil kerja yang telah ditetapkan. Pelatihan yang dilakukan dapat ditujukan baik pada karyawan lama maupun baru. Sedangkan bagi karyawan lama juga perlu belajar dan dilatih dengan tujuan untuk memperbaiki kinerja yang kurang baik, mempelajari pengetahuan dan teknologi serta keterampilan yang baru, juga untuk menyesuaikan dengan perkembangan organisasi dan kebijakan organisasi yang baru.

Pelatihan juga dapat memperbaiki kinerja yaitu karyawan-karyawan yang bekerja secara tidak memuaskan karena kekurangan keterampilan merupakan calon utama pelatihan. Pelatihan dibutuhkan untuk mengisi kekurangan kinerja sesungguhnya dan kinerja terprediksi karyawan. Pelatihan karyawan juga merupakan sebuah proses mengajarkan pengetahuan dan keahlian tertentu sikap agar karyawan semakin terampil dan mampu melaksakan tanggung jawabnya dengan semakin baik dan sesuai dengan standar. Pelatihan biasa merujuk pada pengembangan keterampilan bekerja yang dapat digunakan segera. Menurut Byars dan Ruc dalam Fajar dan Heru (2015:100) pelatihan adalah proses pembelajaran yang melibatkan penguasaan keterampilan, konsep aturanaturan, atau sikap untuk meningkatkan kinerja karyawan. Menurut Desler dalam Fajar dan Heru (2015:100) pelatihan adalah proses pembelajaran keterampilan dasar yang 
dibutuhkan oleh karyawan baru untuk melaksanakan pekerjaannya. Secara prinsip kedua pengertian tersebut adalah sama yaitu pelatihan merupakan proses pembelajaran yang ditujukan kepada karyawan agar pelaksanaan pekerjaannya memuaskan, oleh karena itu perusahaan PT. Essar Dhananjaya harus menyelenggarakan pelatihan serta menunjang sarana dan prasarana harus memadai seperti menyiapkan tempat dan alat-alat yang digunakan dalam pelaksanaan pelatihan.

Dengan adanya pelatihan dalam suatu perusahaan atau organisasi, maka dapat dimungkinkan terjadi peningkatan kinerja, yang juga dikarenakan para karyawan telah memiliki modal atau kemampuan yang cukup untuk mencapai tujuan perusahaan atau organisasi. Perusahaan merasa memerlukan pelatihan bagi karyawan baik karyawan lama maupun karyawan baru guna mencapai tujuannya. Pelatihan memberikan berbagai manfaat, baik kepada perusahaan maupun karyawan itu sendiri. Bagi karyawan, pelatihan member manfaat seperti tambahan pengetahuan, keterampilan kerja, peningkatan prestasi kerja dan sebagainya. Sedangkan bagi perusahaan mereka juga memperoleh manfaat lebih seperti terjaganya stabilitas perusahaan dan karyawan oleh karena itu dalam pelatihan di PT. Essar Dhananjaya harus memiliki semangat yang tinggi untuk mengikuti pelatihan.

Pelatihan karyawan juga merupakan hal yang sangat penting dilakukan oleh sebuah perusahaan, karena dengan dilakukannya pelatihan dalam sebuah perusahaan dapat meningkatkan kemampuan dalam bekerja baik kemampuan fisik maupun kemampuan mental. Selain itu dengan dilakukannya pelatihan kinerja karyawan akan semakin meningkat dan tujuan dari perusahaan dapat tercapai secara meningkat serta dapat menghasilkan pekerjaan dengan kualitas kerja yang dituntut suatu pekerjaan tertentu dengan maksimal. Menurut Mangkunegara (2014:9) bahwa "Kinerja karyawan (prestasi kerja) adalah hasil kerja secara kualitas dan kuantitas yang dicapai oleh seorang pegawai dalam melaksanakan tugasnya sesuai dengan tanggung jawab yang diberikan kepadanya. Oleh karena itu disimpulkan bahwa kinerja SDM adalah prestasi kerja atau hasil kerja (output) baik kualitas maupun kuantitas yang dicapai SDM persatuan periode waktu dalam melaksanakan tugas kerjanya sesuai dengan tanggung jawab yang diberikan kepadanya.

Berdasarkan awal penemuan peneliti dan hasil diskusi dengan pimpinan dan karyawan PT. Essar Dhananjaya. Peneliti menemukan masalah pelatihan dan kinerja. Permasalahan pelatihan yang peneliti temukan antara lain materi pelatihan yang belum sesuai yang diharapkan, masih rendah keterampilan kerja yang belum dimiliki oleh karyawan, fasilitas dan sarana pelatihan yang kurang memadai, minimnya minat peserta pelatihan, dan kualitas kerja yang rendah.

Mengingat pentingnya dan berdasarkan pemikiran tersebut di atas, maka penyusun mencoba melakukan penelitian dengan judul "Pengaruh Pelatihan Terhadap Kinerja Karyawan Pada PT. Essar Dhananjaya di Cibitung-Bekasi”.

\section{B. Rumusan Masalah}

1. Bagaimana pelatihan pada PT. Essar Dhananjaya di Cibitung-Bekasi ?.

2. Bagaimana kinerja karyawan pada PT. Essar Dhananjaya di Cibitung-Bekasi ?.

3. Adakah pengaruh antara pelatihan terhadap kinerja karyawan pada PT. Essar Dhananjaya di Cibitung-Bekasi ?.

\section{Tujuan Penelitian}

1. Untuk mengetahui kondisi pelatihan pada PT. Essar Dhananjaya di Cibitung-Bekasi.

2. Untuk mengetahui kondisi kinerja karyawan pada PT. Essar Dhananjaya di Cibitung- 
Bekasi.

3. Untuk mengetahui pengaruh antara pelatihan terhadap kinerja karyawan pada PT. Essar Dhananjaya di Cibitung-Bekasi.

\section{METODE PENELITIAN}

\section{Populasi}

Populasi dalam penelitian ini berjumlah 100 responden PT. Essar Dhananjaya di Cibitung-Bekasi

\section{Sampel}

Teknik pengambilan sampling dalam penelitian ini adalah sampel jenuh, dimana semua anggota populasi dijadikan sebagai sampel. Dengan demikian sampel dalam penelitian ini sampel yang digunakan berjumlah 100 responden.

\section{Jenis Penelitian}

Jenis penelitian yang dipakai adalah asosiatif, dimana tujuannya adalah untuk mengetahui atau mencari keterhubungan antara variabel independen terhadap variabel dependennya

\section{Metode Analisis Data}

Dalam menganalisis data digunakan uji validitas, uji reliabilitas, analisis regresi linier sederhana, analisis koefisien korelasi, analisis koefisien determinasi dan pengujian hipotesis.

\section{HASIL PENELITIAN DAN PEMBAHASAN}

\section{Analisis Deskriptif}

Pada pengujian ini digunakan untuk mengetahui skor minimum dan maksimum skor tertinggi, ratting score dan standar deviasi dari masing-masing variabel. Adapun hasilnya sebagai berikut:

Tabel 1. Hasil Analisis Descriptive Statistics

\section{Descriptive Statistics}

\begin{tabular}{|ll|r|r|r|r} 
& N & Minimum & Maximum & Mean & \multicolumn{1}{c}{ Std. Deviation } \\
\hline Pelatihan (X1) & 100 & 28 & 44 & 34.14 & 3.864 \\
\hline Kinerja Karyawan (Y) & 100 & 29 & 49 & 38.41 & 4.238 \\
\hline Valid N (listwise) & 100 & & & & \\
\hline
\end{tabular}

Pelatihan diperoleh varians minimum sebesar 28 dan varians maximum 44 dengan ratting score sebesar 3,41 dengan standar deviasi 3,864. Skor ini termasuk pada rentang sakala 3,40-4,19 dengan kriteria baik atau setuju.

Kinerja karyawan diperoleh varians minimum sebesar 29 dan varians maximum 49 dengan ratting score sebesar 3,84 dengan standar deviasi 4,238. Skor ini termasuk pada rentang sakala 3,40 - 4,19 dengan kriteria baik atau setuju.

\section{Analisis Verifikatif.}

Pada analisis ini dimaksudkan untuk mengetahui pengaruh variabel independen terhadap variabel dependen. Adapun hasil pengujian sebagai berikut:

\section{a. Analisis Regresi Linier Sederhana}

Uji regresi ini dimaksudkan untuk mengetahui perubahan variabel dependen jika variabel independen mengalami perubahan. Adapun hasil pengujiannya sebagai berikut: 
Tabel 2. Hasil Pengujian Regresi Linier Sederhana

\begin{tabular}{|c|c|c|c|c|c|}
\hline \multirow[b]{3}{*}{ Model } & \multicolumn{2}{|c|}{ Coefficients $^{a}$} & \multirow{3}{*}{$\begin{array}{l}\text { Standardized } \\
\text { Coefficients }\end{array}$} & \multirow[b]{3}{*}{$t$} & \multirow[b]{3}{*}{ Sig. } \\
\hline & $\begin{array}{r}\text { Unsta } \\
\text { Coe }\end{array}$ & $\begin{array}{l}\text { dardized } \\
\text { ficients }\end{array}$ & & & \\
\hline & B & Std. Error & & & \\
\hline 1 (Constant) & 9.323 & 2.397 & & 3.889 & .000 \\
\hline Pelatihan $(X)$ & .852 & .070 & .777 & 12.209 & .000 \\
\hline
\end{tabular}

Berdasarkan hasil pengujian pada tabel di atas, diperoleh persamaan regresi $\mathrm{Y}=$ $9,323+0,852 X$. Dari persamaan tersebut dijelaskan sebagai berikut:

1) Konstanta sebesar 9,323 diartikan jika pelatihan tidak ada, maka telah terdapat nilai kinerja karyawan sebesar 9,323 point.

2) Koefisien regresi pelatihan sebesar 0,852 , angka ini positif artinya setiap ada peningkatan pelatihan sebesar 0,852 point maka kinerja karyawan juga akan mengalami peningkatan sebesar 0,852 point.

\section{b. Analisis Koefisien Korelasi}

Analisis koefisien korelasi dimaksudkan untuk mengetahui tingkat kekuatan hubungan dari variabel independen terhadap variabel dependen. Adapun hasil pengujian sebagai berikut:

Tabel 3. Hasil Pengujian Koefisien Korelasi Pelatihan Terhadap Kinerja Karyawan.

\section{Correlations $^{\mathrm{b}}$}

\begin{tabular}{llr|r} 
& & Pinerja Karyawan \\
& & Pelatihan $(\mathrm{X} 1)$ & \multicolumn{1}{c}{$(\mathrm{Y})$} \\
\hline Pelatihan $(\mathrm{X} 1)$ & Pearson Correlation & 1 & $.777^{* *}$ \\
\cline { 2 - 4 } & Sig. (2-tailed) & & .000 \\
\hline Kinerja Karyawan $(\mathrm{Y})$ & Pearson Correlation & $.777^{* *}$ & 1 \\
\cline { 2 - 4 } & Sig. (2-tailed) & .000 & \\
\hline
\end{tabular}

Berdasarkan hasil pengujian diperoleh nilai korelasi sebesar 0,777 artinya pelatihan memiliki hubungan yang kuat terhadap kinerja karyawan.

\section{c. Analisis Koefisien Determinasi}

Analisis koefisien determinasi dimaksudkan untuk mengetahui besarnya persentase pengaruh dari variabel independen terhadap variabel dependen. Adapun hasil pengujian sebagai berikut:

Tabel 4. Hasil Pengujian Koefisien Determinasi Pelatihan Terhadap Kinerja Karyawan. Model Summary

\begin{tabular}{lrr|rr|r} 
Model & $\mathrm{R}$ & \multicolumn{2}{c|}{$\begin{array}{c}\text { Adjusted R } \\
\text { Square }\end{array}$} & \multicolumn{2}{c}{$\begin{array}{c}\text { Std. Error of the } \\
\text { Estimate }\end{array}$} \\
\hline 1 & & R Square & .599 & 2.683 \\
\hline
\end{tabular}

Berdasarkan hasil pengujian diperoleh nilai determinasi sebesar 0,603 artinya pelatihan memiliki kontribusi pengaruh sebesar $60,3 \%$ terhadap kinerja karyawan, sedangkan sisanya sebesar 39,7\% dipengaruhi oleh faktor lain yang tidak dilakukan penelitian.

\section{d. Uji Hipotesis}

Pengujian hipotesis dengan uji t digunakan untuk mengetahui hipotesis mana yang diterima.

Rumusan hipotesis: Terdapat pengaruh yang signifikan antara pelatihan terhadap kinerja karyawan. 
Tabel 5. Hasil Uji Hipotesis Pelatihan Terhadap Kinerja Karyawan.

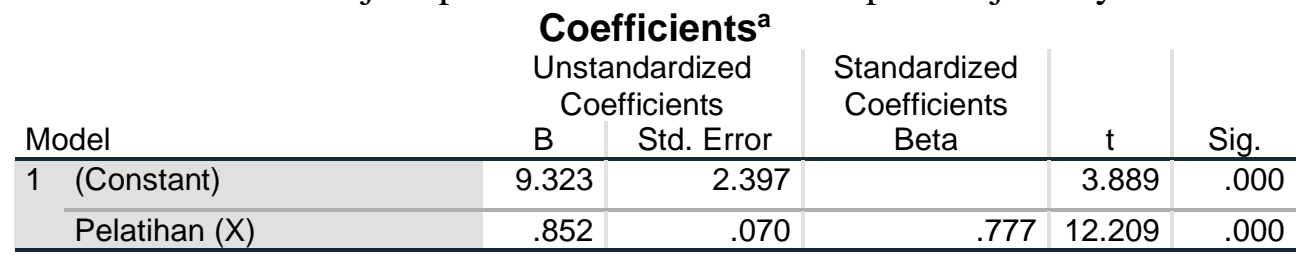

Berdasarkan hasil pengujian pada tabel di atas, diperoleh nilai $t$ hitung $>\mathrm{t}$ tabel atau $(12,209>1,984)$, dengan demikian hipotesis yang diajukan bahwa terdapat pengaruh yang signifikan atara pelatihan terhadap kinerja karyawan diterima.

\section{PEMBAHASAN HASIL PENELITIAN}

\section{Kondisi Jawaban Responden Variabel Pelatihan}

Berdasarkan jawaban responden, variabel pelatihan diperoleh ratting score sebesar 3,41 berada di rentang skala 3,40 - 4,19 dengan kriteria baik atau setuju.

\section{Kondisi Jawaban Responden Variabel Kinerja Karyawan}

Berdasarkan jawaban responden, variabel kinerja karyawan diperoleh ratting score sebesar 3,84 berada di rentang skala 3,40-4,19 dengan kriteria baik atau setuju.

\section{Pengaruh Pelatihan Terhadap Kinerja Karyawan}

Pelatihan berpengaruh signifikan terhadap kinerja karyawan dengan persamaan regresi $\mathrm{Y}=9,323+0,852 \mathrm{X}$, nilai korelasi sebesar 0,777 atau memiliki hubungan yang kuat dengan kontribusi pengaruh sebesar $60,3 \%$. Pengujian hipotesis diperoleh nilai $\mathrm{t}$ hitung > t tabel atau $(12,209>1,984)$. Dengan demikian hipotesis yang diajukan bahwa terdapat berpengaruh signifikan antara pelatihan terhadap kinerja karyawan diterima.

\section{KESIMPULAN DAN SARAN}

\section{Kesimpulan}

a. Variabel pelatihan diperoleh ratting score sebesar 3,41 berada di rentang skala 3,40 4,19 dengan kriteria baik atau setuju.

b. Variabel kinerja karyawan diperoleh ratting score sebesar 3,84 berada di rentang skala 3,40 - 4,19 dengan kriteria baik atau setuju.

c. Pelatihan berpengaruh signifikan terhadap kinerja karyawan dengan persamaan regresi $\mathrm{Y}=9,323+0,852 \mathrm{X}$, nilai korelasi sebesar 0,777 atau kuat dan kontribusi pengaruh sebesar $60,3 \%$ sedangkan sisanya sebesar $39,7 \%$ dipengaruhi faktor lain. Uji hipotesis diperoleh nilai $t$ hitung $>t$ tabel atau $(12,209>1,984)$.

\section{Saran}

a. PT. Essar Dhananjaya perlu meningkatkan pelatihan pada setiap masing-masing divisi departemen dan kepada semua karyawan baru ataupun lama hal ini ertujuan untuk meningkatkan kinerja, produktivitas, pengetahuan, keahlian serta keterampilan.

b. Agar peserta pelatihan mendapatkan banyak pengetahuan dalam mengikuti pelatihan maka PT. Essar Dhananjaya harus lebih memperhatikan dengan cara memfasilitasi pelaksanaan pelatihan dan dengan adanya penyelarasan tugas pegawai dengan kemampuan yang dimilikinya diharapkan apa yang dikerjakan menghasilkan hasil yang maksimal, dengan demikian tingkat kinerja karyawan menjadi lebih baik. 


\section{DAFTAR PUSTAKA}

Abdullah, M (2014) Manajemen dan Evaluasi Kinerja Karyawan, Yogyakarta: Penerbit Aswaja Pressindo.

Affandi, A., Sarwani, A. S., Erlangga, H., Siagian, A. O., Purwanto, A., Effendy, A. A., ... \& Wahyitno, C. D. M. (2020). Optimization of MSMEs Empowerment in Facing Competition in the Global Market during the COVID-19 Pandemic Time. Systematic Reviews in Pharmacy, 11(11), 1506-1515.

Algifari. (2015). "Analisis Regresi untuk Bisnis dan Ekonomi”. Yogyakarta: BPFE.

Arikunto, Suharsimi (2014). "Prosedur Penelitian Suatu Pendekatan Praktek". Jakarta: Rineka Cipta.

Bangun, Wilson. 2012. "Manajemen Sumber Daya Manusia”. Jakarta: Erlangga

Bejo Siswanto (2013) Manajemen Tenaga Kerja Rancangan dalam Pendayagunaan dan Pengembangan Unsur Tenaga Kerja”, Bandung: Sinar Baru.

Dessler, G. (2006.) Manajemen Sumber Daya Manusia (Jilid II). Jakarta: Indeks.

Edi Sutrisno (2016). Manajemen Sumber Daya Manusia. Jakarta: Prenadamedia Group.

George Terry R \& Rue, Leslie W. Rue (2016) Dasar-Dasar Manajemen, Jakarta Bumi Aksara.

Gerry Dessler (2016) Human Resources Management, Prenticehall, London: International Inc.

Handoko (2016) Manajemen Personalia dan Sumberdaya Manusia. Yogyakarta: BPFE.

Handoko T. Hani, (2012), Manajemen Personalia dan Sumber Daya Manusia, edisi kedua, BPFE, Yogyakarta

Hasibuan, Malayu S.P. (2016). Manajemen Sumber Daya Manusia. Edisi Revisi. Jakarta: PT Bumi Aksara.

Imam Ghozali (2017). "Aplikasi Analisis Multivariate Dengan Program SPSS”. Edisi Kelima. Semarang: Badan Penerbit Undip.

Istijanto (2014) "Riset Sumber Daya Manusia”. Jakarta: PT. Gramedia Pustaka

Jasmani, J., \& Paeno, P. (2019). The Effect of Leadership and Competence on Lecturer Performance and Its Implications on Student Learning Motivation at Pamulang University. International Journal of Advances in Social and Economics, 1(4).

Kaso, N., Nurjihad, A., Ilham, D., \& Aswar, N. (2021). Facebook and its Impact on Students' Learning Achievement at State Islamic High School of Palopo. Jurnal Studi Guru dan Pembelajaran, 4(1), 1-15.

Luthans Fred (2014) Organizational Behavior, Ney York: McGraw-Hill, New York.

Mangkunegara, Prabu Anwar. (2016). Evaluasi Kinerja SDM. Cetakan ke tujuh, PT Refika Aditama: Bandung.

Mulyadi, M. (2018). Pengaruh Pelatihan Dan Motivasi Terhadap Kinerja Karyawan Pada PT. Permata Lestari. JENIUS (Jurnal Ilmiah Manajemen Sumber Daya Manusia), 2(1).

Muslimat, A., Muhsin, H., Wahid, H. A., Yulistiana, I., Sunarsi, D., Dewi, K., ... \& Ilham, D. (2021). Develop Technology Based Multimedia For Indonesian Teachers. Journal of Contemporary Issues in Business and Government, 27(1), 1871-1882.

Permatasari, R. J. (2018). Analisis Pengaruh Pendidikan Dan Pelatihan, Motivasi Dan Kompensasi Terhadap Kinerja Karyawan (Pada Citibank Pondok Indah Jakarta Selatan). JENIUS (Jurnal Ilmiah Manajemen Sumber Daya Manusia), 1(3).

Purwanti, Y. (2021). The Influence Of Digital Marketing \& Innovasion On The School Performance. Turkish Journal of Computer and Mathematics Education (TURCOMAT), 12(7), 118-127. 
Robbins, P.S, \& Judge, A.T. (2003). Organizational Behavior. Jakarta: Salemba Empat. Santoso, Singgih (2015). "Menguasai Statistik Multivariat". Jakarta: PT Elex Media Komputindo.

Sedarmayanti (2016) Manajemen Sumber Daya Manusia, Reformasi Birokrasi dan Manajemen Karyawan Negeri Sipil, Cetakan Kelima, Bandung: PT Refika Aditama. Sudjana (2014) "Metode Statistika", Bandung: Tarsido.

Sugiyono (2017), "Metode Penelitian Administrasi : dilengkapi dengan Metode $R \&$ D”. Bandung: Alfabeta.

Suhartanto (2014). “Metode Riset Pemasaran”. Bandung: Alfabeta

Sunarsi, D. (2019). Penerapan MSDM Strategis Dalam Upaya Meningkatkan Kemampuan Organisasi dalam menyongsong Revolusi 4.0. Jurnal Ilmiah MEA (Manajemen, Ekonomi, \& Akuntansi), 3(1), 221-233.

Veithzal Rivai (2015) Manajemen Sumber Daya Manusia Untuk Perusahaan, Jakarta: Raja Grafindo Persada.

Wibowo (2015) Manajemen Kinerja, Jakarta: PT. Raja Grafindo Persada. 